\title{
O PAPEL DO PROFESSOR NO DESENVOLVIMENTO DA SENSOPERCEPÇÃO EM NADADORES
}

\author{
Carolina Mie Kawagosi Onodera \\ Universidade Estadual de Campinas, Campinas, São Paulo, Brasil \\ Angela Nogueira Neves Betanho Campana \\ Escola de Educação Física do Exército, Rio de Janeiro, Rio de Janeiro, Brasil \\ Maria da Consolacao Gomes Cunha Fernandes Tavares \\ Universidade Estadual de Campinas, Campinas, São Paulo, Brasil
}

\begin{abstract}
Resumo
A sensopercepção é a percepção das sensações internas que são geradas por meio da experiência corporal. Frente a esta realidade o papel do profissional de educação física também se torna fundamental uma vez que conduz essas práticas corporais. O objetivo do presente estudo foi mostrar a importância do professor de natação no processo de desenvolvimento da sensopercepção do aluno. A valorização do processo de sensopercepção contribuiu não só para o aprimoramento técnico nas práticas de atividade física, como promoveu nos alunos um aprendizado de melhor cuidar, valorizar e respeitar o próprio corpo. O projeto mostrou uma boa aderência pelos participantes.
\end{abstract}

Palavras Chave: Natação. Sensação. Percepção.

\section{Introdução}

${ }^{117}$ Esse estudo surgiu pelo interesse de refletir sobre a responsabilidade dos profissionais da área de educação física na condução das práticas corporais. Dessa forma nosso amplo campo de atuação abrange não só o ensino das técnicas, mas também a possibilidade de contribuir na formação dos indivíduos. Esse trabalho visa mostrar a relevância do professor de educação física no desenvolvimento das habilidades de sensopercepção dos alunos. Diante disso foi preciso expor alguns conceitos de percepção nos quais nos baseamos para realizar este trabalho.

Segundo a Associação Americana de Psicologia (VANDENBOS, 2010, p.695), Percepção pode ser definida como:

Processo ou resultado de se tornar consciente de objetos, relacionamentos e eventos por meio dos sentidos, que inclui atividades como reconhecer, observar e discriminar.

117 Esta pesquisa foi financiada pelo $\mathrm{PIBIC} / \mathrm{CNPq}$ 
A percepção teria duas operações relacionadas: (1) identificação da informação, que diz respeito à captação do objeto em sua totalidade e (2) reconhecimento de diferenças e semelhanças entre o que é e o que já foi percebido (MARINA, 1995).

Essas atividades permitem que os seres humanos se organizem e interpretem os estímulos recebidos em conhecimento significativo (VANDENBOS, 2010, p. 695).

Sensação, por sua vez, pode ser definida como:

1 - o processo ou experiência de perceber através dos sentidos. 2 - unidade irredutível de experiência produzida por estimulação de um receptor sensorial e a resultante ativação de um centro cerebral específico produzindo consciência básica de um som, odor, cor, forma, ou gosto ou de temperatura, pressão, dor, tensão muscular, posição do corpo ou mudança nos órgãos internos. (VANDENBOS, 2010, p.833).

Por tanto consideramos aqui que a sensação também é uma forma de percepção.

Corroborando com nossa linha de pesquisa, Antônio Damásio ${ }^{118}$ (2009), chama de sentimentos primordiais, o que entendemos como sensações, esses sentimentos primordias se baseiam em emoções e funcionam, conforme o autor, como marcadores somáticos. Esses marcadores somáticos formam mapas cerebrais que são alimentados por uma alça ressonante, que a todo momento leva e traz informações de uma parte do corpo para outra. Dessa forma, "corpo" e cérebro não estão dissociados e formam uma unidade. Entende-se então que corpo e cérebro são estruturas que coexistem e ambas pertencem ao corpo, apenas ocupam lugares diferentes. Segundo o mesmo autor esses mapas são imagens e muitas vezes vêm acompanhadas das sensações que levarão à formação da consciência.

Ressalta-se que a percepção - do corpo ou de objetos externos a ele - não é somente um processo mental, mas antes, outras regiões do corpo são protagonistas desse processo (DAMÁSIO, 2011, p. 121).

Outro estudioso da percepção, Peter Levine ${ }^{119}$, afirma que o desenvolvimento das habilidades de perceber as sensações, criam especializações sobre este aspecto, como por exemplo, a sensopercepção.

Esse trabalho trata dessa modalidade, a sensopercepção.

Para Levine e Frederick (1999) a sensopercepção é a percepção das sensações internas que são geradas por meio da experiência corporal. É uma habilidade acessível a todos. (LEVINE, 2012).

A técnica corporal "Somatic Experiencing", desenvolvida por Peter Levine (1999), para pessoas com estresse pós-traumático tem no desenvolvimento da sensopercepção sua "pedra fundamental". É um processo no qual a pessoa pode encontrar os sintomas ou reflexos

118 Antônio R. Damásio ocupa a cadeira de David Dornsife de neurociência, psicologia e neurologia na Universidade do Sul da Califórnia, em Los Angeles, nos Estados Unidos, onde também dirige o Instituto do Cérebro e da Criatividade. Integra o Instituto de Medicina da Academia Nacional de Ciências dos Estados Unidos, a Academia Européia de Ciências e Artes e a Academia Bávara de Ciências.

119 Peter Levine Recebeu seu Ph.D. em física médica e biológica pela Universidade da Califórnia, em Berkeley, e obteve o grau de doutor em psicologia pela International University. Foi consultor da NASA durante o desenvolvimento do Ônibus Espacial e lecionou em hospitais e clínicas de dor tanto na Europa quanto nos Estados Unidos. É consultor do Pain-Rehabilitation Center in Boulder, Colorado. Em seus trinta anos de estudo sobre o estresse e o trauma, contribuiu com muitas publicações médicas e científicas, incluindo o capítulo sobre o stresse no Handbook of Psychophysiology. 
do trauma. Ao dirigir a atenção para as sensações internas do corpo, ao invés de reviver o trauma, pode renegociar o trauma e as sensações geradas, possibilitando a reintegração e a regulação do sistema nervoso autônomo (LEVINE \& FREDERICK, 1999).

Embora tenha sido desenvolvida para pessoas com estresse pós-traumático o "Somatic Experiencing" é uma técnica que não precisa se limitar a este cenário, mas pode ser aprendida e usada para promover o desenvolvimento do ser humano de uma forma integradora, promovendo uma ampliação de suas relações com o mundo e consigo próprio (TAVARES, 2003).

Apesar do evidente protagonismo do corpo na experiência das sensações a sensopercepção ainda é um fenômeno pouco conhecido na área da Educação Física. $O$ profissional de educação física pode ter um papel fundamental no processo de desenvolvimento da sensopercepção uma vez que está em contato direto com seus alunos, podendo estimulá-los a movimentos e vivências corporais, gerando sensações a todo instante. É preciso que seja assumida e valorizada a presença real do professor em toda a intervenção corporal. (TAVARES, 2003, p. 142).

A prática de atividade física proporciona uma infinidade de possibilidades de sensações, estímulos e vivências, assim gera múltiplas formas de experiência. O profissional de educação física, através do movimento, pode favorecer a ampliação da consciência dessas sensações, promovendo o desenvolvimento de seu aluno. Nessa perspectiva, as experiências corporais na aula de educação física, na academia, nas praças de esporte são espaços de potencial crescimento do mesmo, com a ampliação de seu contato interno.

Todavia, esta perspectiva é pouco explorada na área da educação física (CABRAL, 2004), o estudo mais recente que tivemos acesso tratava do desenvolvimento da percepção em nadadores com o objetivo de avaliar a contribuição da percepção na formação do esquema corporal feito por Gama e colaboradores em 2009.

O presente trabalho justifica-se pela necessidade de aprofundar o conhecimento da sensopercepção e ampliar a disseminação desse enfoque na condução das práticas corporais no desenvolvimento do sujeito. Sendo o movimento humano a área de conhecimento específico da Educação Física, fica evidente a necessidade de se apropriar com mais consistência desse tema, ressaltando a importância da sensopercepção nas aulas de natação.

\section{Objetivos}

Este trabalho teve como objetivo mostrar a importância do professor de natação no processo de desenvolvimento da sensopercepção do aluno.

\section{Métodos}

O método utilizado para avaliação do ensino de natação com enfoque no desenvolvimento da sensopercepção foi a implantação de um programa realizado em três etapas: planejamento, avaliação e por fim a intervenção prática.

Trata-se de uma pesquisa descritiva e exploratória (THOMAS e NELSON, 2002), aprovada pelo Comitê de Ética e Pesquisa da Faculdade de Ciência Médicas da Universidade Estadual de Campinas, sendo o Certificado de Apresentação para Apreciação Ética (CAAE) o número 10787212.0.0000.5404. 


\section{Planejamento}

Para a criação do programa de desenvolvimento da sensopercepção na natação, a pesquisadora participou do projeto de monitoria em duas turmas de extensão em natação na Faculdade de Educação Física da Unicamp durante um semestre que antecedeu o início da pesquisa, a fim de tomar conhecimento do local da intervenção, suas rotinas e as características das turmas.

Paralelamente, foi feita uma revisão bibliográfica com o objetivo de aprofundar os conhecimentos sobre o fenômeno da sensopercepção e estratégias para o seu desenvolvimento. Escolhemos a abordagem de Levine $(1999,2012)$ para conduzir as ações em relação as estratégias para sensibilizar a percepção dos alunos fundamentada na ferramenta "Somatic Experience". Procuramos criar espaços para que os alunos pudessem sentir suas próprias sensações e validá-las.

Dessa forma, na condução das aulas de natação, a pesquisadora criou estímulos orais para que os alunos ficassem atentos aos seus estados internos. Frases como: "Como está se sentindo hoje?", "Como está a temperatura do seu corpo em relação a água?","Perceba seu corpo deslizando na água" e "Repare, sinta se o movimento gera alguma sensação interna" foram usadas, assim como questionamentos: "Como estava o posicionamento da sua cabeça durante o nado?","Como estava a sua respiração durante o nado? E o ritmo da sua pernada?", "Como estava o nível de tensão do seu pescoço? (podendo variar a região do corpo)", "O seu nado está confortável?". A partir das reflexões dos próprios alunos a professora sugeria algumas mudanças e correções. Ao final da aula o alunos tinham sempre de 05 a 10 minutos para "soltarem o corpo". Neste momento a professora sempre estimulava os voluntários a perceberem o corpo, relaxarem os músculos que estavam muito tensionados, sentirem as sensações enquanto nadavam. Porém o treino e exercícios eram passados normalmente.

Inicialmente, foi estruturada a periodização da intervenção, para um período de 30 aulas, com duração de uma hora, sob o sistema de cargas ondulatórias apresentada por Matveev em 1950, que visa o trabalho de diversas capacidades físicas simultâneamente (ANDRIES JÚNIOR et al., 2010, p. 71).

Escolheu-se a natação para o desenvolvimento da pesquisa. A técnica específica da natação pode ser adaptada a peculiaridade de cada sujeito, e dessa forma, cada sujeito tem a possibilidade de ter o seu nado, segundo as diretrizes básicas da natação (REIS, 1983). A natação é reconhecida como um esporte ideal por excelência, não só pelo fato de poder ser praticada por qualquer pessoa, sem distinção de idade, que tenham ou não deficiências sensorial, física ou intelectual - mas também por seu valor formativo e totalizador (DAMASCENO, 1997). A imersão em meio líquido oferece múltiplas sensações, tanto em qualidade - pressão, temperatura - quanto em quantidade.

Em segundo lugar foram selecionadas atividades para as aulas de natação. A periodização foi estruturada com um enfoque para o aprimoramento das técnicas dos nados crawl, costas, peito e borboleta, com o objetivo também de melhorar o desempenho como um todo.

A respiração foi um aspecto muito trabalhado. Segundo Maglischo (1999, p.34) os nadadores devem aprender esta habilidade particularmente bem, pois o controle da respiração influencia o ritmo de suas braçadas, em outras palavras, o controle da inspiração e expiração é fundamental para que se mantenha um ritmo de nado. Utilizamos diversos exercícios educativos para a respiração predominantemente os nados crawl e peito, com a finalidade 
principal de o aluno aprender a controlar a fase de expiração em diferentes tempos. Assim os alunos foram estimulados durante a aula a sempre prestarem atenção na respiração.

Entendemos também que o alinhamento do corpo, posicionamento (equilíbrio), e flutuação são questões muito importantes que foram também trabalhadas, visando diminuir o arrasto de forma (MAGLISCHO, 1999, p.284), para que assim os alunos tivessem maior aproveitamento no deslize e propulsão do nado. Segundo Andries Júnior (2008, p.87) a flutuação precede de um certo controle respiratório, uma descontração corporal e localização espaço/ temporal. Seguindo esta lógica para a melhora da flutuação e alinhamentos do corpo foram passados alguns exercícios de controle respiratório, além de exercícios que estimulavam os alunos a vivenciarem diversas posições do corpo na água.

Para o aprimoramento do nado em geral, da técnica de cada estilo, coordenação, força, velocidade e resistência, foram passados exercícios para os membros superiores e membros inferiores de maneira isolada, para que os alunos pudessem ter melhor percepção e atenção no educativo. $\mathrm{O}$ nado era realizado também de maneira completa, para que não se perdesse a especificidade do estilo. Para isso utilizamos materiais auxiliares como flutuador, nadadeira, palmar e prancha.

Como a turma em questão era heterogênea, foram passados educativos específicos de cada nado de acordo com a necessidade de cada aluno, as metragens também foram adaptadas de acordo com o estágio de cada um.

As sessões de treino obedeceram a uma estrutura dividida em três partes: aquecimento, série principal e de apoio e volta à calma (ANDRIES JUNIOR et al., 2010, p.69).

\section{Avaliação}

Para avaliação do programa foram utilizados dois parâmetros: o primeiro, quanto as evidências da apreciação do mesmo, sendo avaliado sob dois aspectos, as impressões dos próprios alunos e quanto aderência dos mesmos ao programa. E o segundo pelas evidências de efetividade.

Para a avaliação das impressões dos alunos foi solicitado um relato escrito ao final do curso, sobre a experiência de ter participado do projeto. Quanto a aderência dos participantes, foi considerado a ficha de frequência dos mesmos, bem como o número inicial e final de voluntários participantes.

Para a avaliação das evidência de efetividade foi elaborado pela pesquisadora um "diário de sensações", um caderno entregue para os alunos, a fim de que pudessem anotar alguma observação em relação às aulas e suas sensações.

As perguntas norteadoras do diário de sensações foram: (1) Quais sensações eu senti hoje na aula de natação? (2) Enquanto nadava outros pensamentos ou emoções externos à atividade ocorreram? Se sim, quais seriam eles?

Essas perguntas norteadoras passaram pelo julgamento de cinco especialistas em validação de questionários na área de educação física, para que fossem verificadas quanto à pertinência (MINAYO, 1999). Este diário foi entregue para os voluntários no primeiro dia de aula.

Os voluntários foram orientados para que escrevessem no diário sempre que sentissem necessidade, porém foi estimulado que eles escrevessem sempre em seguida das aulas.

A análise dos dados do diário de sensações assim como do relato final foram feitas com análise de conteúdo Segundo Bardin (2002, p. 38). Depois da coleta das informações dos dois instrumentos, procedemos com a leitura atenta para codificação do material. 
Estabelecemos uma série de códigos (letras) que se referiam às questões originais dos instrumentos para identificar conteúdos que pudessem apontar para (a) a apreciação do programa e (b) para o desenvolvimento da habilidade de perceber as sensações. Em seguida, relemos material com as marcações, organizando-as dentro dos temas.

\section{Intervenção prática}

Com a finalização do planejamento e as formas de avaliação, foram tomadas medidas para que o programa fosse de fato implantado, de modo a dar início a intervenção prática. A pesquisadora divulgou o projeto de pesquisa no site da Faculdade de Educação Física de Unicamp, além disso foi divulgado em espaços públicos da comunidade universitária através de cartazes.

Os voluntários interessados em participar do estudo, manifestaram interesse por e-mail e assim preencheram uma ficha cadastral. A pesquisadora entrou em contato por e-mail, avisando o local, dia e horário do início das aulas. Como a demanda de voluntários foi muito alta, a seleção foi feita por ordem de manifestação de interesse, foram selecionados 13 participantes, por conta da limitação de espaço.

No primeiro dia de aula foi ressaltado que a participação era voluntária e as aulas não teriam nenhum custo por se tratar de um projeto de pesquisa. Após o esclarecimento das dúvidas, foi informado que poderiam participar da pesquisa mediante a assinatura do Termo de Consentimento Livre e Esclarecido e apresentação de atestado médico, liberando para a prática de atividade física, foi dado o prazo de um mês para que trouxessem o mesmo.

As aulas tiveram duração de 60 minutos, com frequência de três vezes por semana, com duração de 12 semanas e foram oferecidas na piscina da FEF (Faculdade de Educação Física da Unicamp). Todas as aulas foram oferecidas pela pesquisadora.

\section{Análise dos dados}

Compareceram 13 participantes na primeira aula de natação na Faculdade de Educação Física da Unicamp. Dos 13 participantes iniciais, 11 concluíram o programa para o desenvolvimento da sensopercepção. A primeira desistência ocorreu na sétima semana e a segunda na nona semana. Entramos em contato com os participantes para saber os motivos que os levaram a desistência. Foi comunicado que a desistência não se dava por conta de problemas relacionados ao programa, nem por dificuldades com as aulas, nem por qualquer mal estar relacionado à proposta. Foram compromissos acadêmicos dos participantes que os levaram a mudar de cidade/ reduzir o tempo livre que os impediu de continuar.

Um total de 11 pessoas participaram do estudo, 04 mulheres e 07 homens. A idade dos participantes variou entre 20 e 53 anos $(M=33,27 ; D P=8,84)$ e o valor médio do índice de massa corporal (IMC) foi de $24,31 \mathrm{~kg} / \mathrm{m} 2(D P=2,09)$. A maioria dos participantes descreveram-se como fisicamente ativos antes do início do projeto $(81,82 \%)$.

Podemos considerar que o projeto teve uma boa aderência dos participantes. No geral a frequência dos participantes nas aulas foi constante representando uma média de presença de $92,5 \%$ durante todo o programa Dos participantes da pesquisa $72,73 \%$ possuíam vínculo acadêmico e a frequência dos mesmos estava muito relacionada a este fator, ao passo que as faltas, foram justificadas muitas vezes por conta de congressos, cursos e palestras aos quais os alunos precisavam participar e/ou ministrar. 
Ao analisarmos os instrumentos de coleta sobre a avaliação das impressões dos alunos sobre o projeto observamos que o este foi bem avaliado tanto nas atividades propostas, bem como na forma com que as mesmas foram conduzidas, juntamente com a postura da pesquisadora nos momentos de propor as atividades e corrigi-las.

Nos relatos foram identificados indícios de que o projeto piloto teve uma boa aceitação e uma boa apreciação. Todos os participantes demonstraram nos relatos, grande satisfação e gratidão por terem participado do projeto, por terem evoluído tecnicamente, melhorado o condicionamento físico, por terem tido tempo, espaço de aprendizado e descobertas sobre eles mesmos. Esses aspectos podem ser ilustrados nas seguintes falas:

Confesso que, quando comecei os treinamentos sob a proposta de ser um treino baseado na sensopercepção dos nadadores, não tinha uma ideia clara do que se tratava exatamente. Ao longo destas semanas e através da guia da professora tenho podido observar, perceber, não só meus movimentos, mas a própria sensação de nadar. [...] Sem dúvida tem sido não só útil, mas prazeroso participar desta pesquisa. (Indivíduo 2)

Adorei o nosso semestre de natação e gostei muito de participar da pesquisa. No começo do semestre, imaginei que ia praticar os nados sem aprender algo novo, afinal era só uma pesquisa. Mas os toques que a professora dava a cada aula eram sempre muito úteis e dava para sentir que ela realmente estava nos acompanhando de perto enquanto nadávamos, atendendo bem as deficiências tanto dos meus colegas quanto as minhas, sempre respeitando as nossas limitações. Acredito que esses detalhes que ela percebia (e nos ajudava a perceber) em nosso nado, contribuíram bastante para melhorar e principalmente nos sentirmos mais confortáveis enquanto nadamos. (Indivíduo 03)

[...] Gostaria de colocar que o hábito de escrevermos sobre nós mesmos em um caderno, uma espécie de diário, extrapolou as aulas não apenas no que se refere às minhas reflexões como também adotei essa postura de ter um diário, um caderno de anotações, no qual escrevo quando estou com inquietações. Gostei bastante das aulas. [...] Além disso, ela era muito atenciosa não apenas conversando com a gente como também prestava atenção em nossos nados e nos auxiliava a corrigi-los para melhor aproveitarmos o movimento do nosso corpo. Nesse sentido, levo comigo coisas muito positivas e profundas dessas aulas de natação, uma experiência significativamente diferente dos outros semestres em que fiz extensão de natação na Faculdade de Educação Física da Unicamp. (Indivíduo 5)

Foi um prazer e um privilégio participar desse projeto, [...] comecei a gostar muito de nadar e todas as reflexões aprendidas durante a aula, agora já fazem parte de mim. Desta forma, aprendi a me respeitar, a me valorizar, o projeto me proporcionou auto conhecimento, auto estima, as aulas eram equilíbrio entre o prazer e a determinação, a professora nos conduziu de forma a nos fazer refletir sobre os movimentos e descobrir nosso corpo. Fez isso com muita sabedoria, mudando os exercícios, estilos de nado, etc. É muito diferente quando alguém lhe fala alguma coisa e quando você percebe, você se percebe. [...] mesmo embaixo de chuva e frio eu tive vontade de ir às aulas. (indivíduo 11)

Não houve nenhum registro negativo por parte dos participantes em relação ao projeto desenvolvido. 
A avaliação subjetiva da sensopercepção foi tomada como parâmetro para a avaliação da efetividade do programa. Tomamos como referência para análise destes dados as categorias de sensopercepção descritas por Levine e Frederick (1999). As categorias são: sensação (pressão, corrente de ar, tensão, dor, formigamento, coceira); temperatura; tamanho; forma; peso; velocidade; textura; cor; humor/ emoção; som; sabor; cheiro; "o nada" e o movimento (HANSON, 2013). Em nosso programa para o desenvolvimento da sensopercepção, foram identificados as seguintes qualidades de sensopercepção por meio dos registros feitos pelos participantes: sensação (pressão, corrente de ar, tensão, dor), temperatura, peso, velocidade, cor, humor/ emoção e o movimento.

Os sentidos físicos (externos) como a visão, audição, olfato, paladar e tato, são elementos que contribuem apenas com parte da informação que constrói o alicerce da sensopercepção (LEVINE, FREDERICK, 1999). Por meio dos canais externos além da visão, o indivíduo pode formular imagens mais complexas de certa experiência que vivênciou (LEVINE, 2012). Essas impressões visuais ou imagens são a forma primordial que os seres humanos modernos utilizam para acessar e armazenar informações sensoriais externas (LEVINE, 2012, p. 136). A cor vista pelo participante por meio de uma percepção visual que foi registrada e posteriormente acessada, gerou um certo comportamento (nadar contraindo muito os músculos) que estava intimamente ligado a uma emoção do participante.

Percebi que tenho certo desconforto na água, nado todo contrído mesmo, lembrei que quando era mais novo tinha medo do azul da piscina, quando não consigo ver o outro lado da piscina ou seu fundo e fica aquela coloração azul. O engraçado é que soa cotraditório, pois ao mesmo tempo que tenho esse medo e gosto de nadar. (Indivíduo 5)

Segundo Levine (2012) a impressão tátil que a pessoa experiencia, é composto tanto de uma impressão externa quanto de uma sensação interna. Assim, a sensação de corrente de ar tocando a pele e o não sentir frio por conta do exercício físico podem ser exemplos do que Levine nos coloca.

A aula foi maravilhosa! Com muito vento, mas o treino não nos deixou sentir frio... (Participante 7)

O tempo ajudou muito hoje, sem ventos e sem frio... (Participante 7)

Ou em relação a temperatura de forma mais direta, a água gelada tocando a pele e a sensação de frio,

O que senti hoje, principalmente no início da aula foi frio. A água estava muito gelada. Mas depois com o tempo a água vai se tornando mais agradável. (Participante 5)

Por causa do frio estava difícil de relaxar. (Participante 03)

Ou ainda a sensação da água tocando a pele e uma sensação agradável,

A água estava boa, dando uma sensação gostosa ao nadar. (Participante 3)

A água da piscina está uma delícia. (Participante 7) 
Outros dados importantes vêm de nossa percepção corporal interna (a posição em que o corpo está, as tensões que ele tem, os movimentos que ele faz, temperatura, etc.) (LEVINE, FREDERICK, 1999, p. 70). A percepção mais íntima que temos de nós mesmos se dá por meio da propriocepção, da cinestesia, e da sensação visceral. Segundo Levine (2012) o primeiro subsistema dentro do canal da sensação é a cinestesia. O sentido cinestésico sinaliza o estado de tensão em nossos músculos e retransmite essa informação para o cérebro. Se você se sente "incomodado" e/ou "tenso", é porque esta recebendo um excesso de impulsos nervosos provenientes dos músculos dos ombros e de outras áreas. Como descritos abaixo:

As sensações de tensão:

Hoje um pouco tensa, alguns pontos muito tensionados, principalmente meu pescoço. (Participante 7)

Durante a aula hoje senti meu corpo totalmente relaxado e tive um nado bem confortável. (Participante 9)

Sinto que pescoço e ombros ainda estão tensionados. (Participante 6)

Hoje apenas senti uma leve tensão nos ombros, mas ao longo da aula foi diminuindo gradativamente. Há regiões do meu corpo onde ela frequentemente se acumula, como nos ombros, ao longo da coluna ou na região lombar. (Participante 10)

As sensações de pressão:

Durante o nado costas senti meu corpo mais relaxado do que com o nado crawl, apesar da pressão ao redor do pescoço. (Participante 9)

E por fim as sensações de dor (incômodo):

As dores no ombro desapareceram por definitivo. (Participante 6)

Hoje estou com dor no peito e percebi que tive dificuldade para respirar do lado esquerdo. (Participante 11)

Depois das dores nas pernas da quarta-feira, hoje sexta-feira elas voltam mas com menor intensidade. (Participante 4)

Para Levine (2012) os receptores vestibulares são os responsáveis pelas informações que nos indicam tanto a nossa posição como nossa velocidade.

Tinha horas que sentia um prazer imenso, sentindo meu corpo deslizando na água com muita rapidez. (Participante 7)

Tive que diminuir a velocidade para controlar a respiração. Nadei mais devagar do que gostaria. (Participante 11) 
Sengundo Levine e Frederick (1999, p. 74) ao entrar em contato com a sensopercepção a informação virá para o sujeito sob forma de palavras, imagens, insights e emoções que invariavelmente serão acompanhadas por outra camada de sensações. Como podemos ver nos relatos dos participantes da pesquisa, as emoções muitas vezes vem vinculada à sensações. A sensação de peso, como no exemplo abaixo estava associada a outra sensação de falta de coordenação, e ainda de não estar se sentindo bem.

Achei também que hoje não estava muito bem, às vezes me sentia pesada e muito desgovernada. (Participante 7)

O ato de sentir é um processo contínuo que envolve vários níveis de prazer e desprazer (LEVINE, 2012, p. 268). Podemos observar melhor a qualidade de sensopercepção de humor/ emoções nos relatos abaixo, ligados a esse prazer e desprazer citados por Levine e Frederick (1999).

Cansada sim! E muito feliz! (Participante 7)

É complicado tentar render na piscina e sentir que o corpo não corresponde segundo as expectativas. Isso causa frustração. (Participante 2)

Acho que hoje tive um pouco a sensação de satisfação. Essa mistura de cansaço mas com adrenalina e satisfação. (Participante 2)

Hoje fiquei contente ao perceber, depois de tantos exercícios específicos, que consigo deslizar na água no nado peito, e o quanto esse deslize é divertido. (Participante 10)

Foi uma experiência muito boa e prazerosa. (Participante 4)

A sensopercepção pode também aumentar o nosso senso de equilíbrio e de coordenação. (LEVINE, FREDERICK, 1999, p. 72). Ao tomar consciência dos próprios comportamentos, a pessoa pode incorporar essas percepções a seu papel de observador, e lembrar a si mesmo de notar as sensações associadas a esses comportamentos (LEVINE, 2012, p. 143). Bem como nos movimentos.

Aprendi que tenho um eixo, que me faz deslizar mais no nado peito. Encaixando bem a cabeça e abaixando entre os braços a flutuação é melhor e deslizo mais. (Participante 7)

Hoje tive a sensação de mais controle do meu corpo dentro da água. (Participante 6)

Estou controlando melhor o crawl, tanto as passadas de braço e perna, como o ritmo de respiração. (Participante 6)

Hoje consegui sentir meu corpo trabalhando de modo mais harmônico. (Participante

Por fim, ressaltamos que nenhuma sensopercepção das categorias de formigamento, coceira, tamanho, forma, textura, som, sabor, cheiro e "o nada" foram registrado pelos participantes. 


\section{Discussão}

O principal objetivo do presente estudo foi mostrar a importância do professor de natação no processo de desenvolvimento da sensopercepção do aluno, através do conceito formulado por Peter Levine. Para isso registramos todo o processo de criação do programa para o desenvolvimento da sensopercepção, podendo assim ser utilizado para pesquisas futuras ou como uma forma de intervenção diária.

O programa foi oferecido durante três meses: fevereiro, março e abril do ano de 2013, com frequência de três vezes por semana, com duração de uma hora. As aulas de natação foram ministradas na piscina da Faculdade de Educação Física da Unicamp.

O espaço em que trabalhamos não era um espaço reservado, assim o fluxo de pessoas passando dentro e fora da área da piscina era grande, podendo causar algum constrangimento e dificuldade de concentração dos participantes, além disso a piscina não era coberta, o que causou a interrupção de algumas aulas por conta do tempo de chuva com raios.

O curto espaço de tempo do projeto piloto não permitiu que pudéssemos trabalhar de uma forma mais aprofundada e ao mesmo tempo ampliada nas questões da sensopercepção, sendo este um limite da nossa pesquisa.

Um ponto importante a ser destacado foi quanto a efetividade do projeto piloto, constatamos que o mesmo conseguiu abordar 10 de 19 qualidades da sensopercepção citadas por Levine. Outro ponto importante a ser considerado foi a boa aderência, no início tivemos todas as vagas preenchidas e apenas duas desistências ao longo do projeto, totalizando 11 participantes ao final da pesquisa que estiveram presentes assiduamente. Além disso os mesmo mostraram grande apreciação pelo projeto piloto.

Entendemos que a sensopercepção é um fenômeno que deve ser melhor explorado, sendo este programa para o desenvolvimento da sensopecepção uma contribuição inicial para o que deve ser ainda estudado. Assim outras práticas corporais podem servir de base para o aprimoramento da consciência dessas sensações. Sugere-se também a elaboração de um questionário futuro com escala de medida, já que possuímos alguns dados qualitativos para que essa elaboração seja possível.

\section{Considerações Finais}

Concluímos que o programa proposto para o desenvolvimento da sensopercepção foi capaz de identificar estratégias que tornassem os alunos mais atentos as próprias sensações através de estímulos como a fala e as anotações realizadas nos diários de sensações.

Essas estratégias enriqueceram a sensopercepção em praticantes de natação. Foram encontrados nos resultados os mais variados sentimentos, sensações e emoções. Sendo esta a realidade do corpo, um fenômeno complexo.

A partir da análise dos dados obtidos pudemos constatar que a intervenção realizada juntamente com o exercício da escrita no diário, foram eficientes no processo de tomada de consciência das sensações corporais dos voluntários, criando um espaço para que essas fossem validadas.

Percebeu-se que o papel do professor é igualmente importante no aprimoramento da sensopercepção, foi apontado que este esteja sempre atento as necessidades de cada um, reconhecendo-os como únicos, respeitando o espaço, o tempo, os limites dos indivíduos e principalmente validando suas sensações. Um ambiente confortável foi apontado como uma referência de segurança e importante para o processo de desenvolvimento individual. 
O estímulo à sensopercepção facilitou não só a percepção das sensações, mas sensibilizou-os para a percepção dos movimentos, tanto os alunos como a professora observaram maior facilidade na correção das técnicas dos nados. Assim a valorização do processo de sensopercepção contribuiu significativamente para o aprimoramento técnico nas práticas de atividade física.

Além disso, a sensopercepção promoveu nos alunos/clientes um aprendizado de melhor cuidar, valorizar e respeitar o próprio corpo uma vez que é um fenômeno que extrapola as bordas da piscina, amplia horizontes e possibilidades de escolhas dos caminhos a trilhar na vida, contribuindo também para a formação da identidade do sujeito.

Ter uma relação de intimidade com nossas sensações físicas e compreende-las é fundamental, pois, ao sinalizar a ação, elas nos guiam pelas experiências, vivências e nuanças da vida. (LEVINE, 2012, p. 130)

Assim a abordagem humanizada e cuidadosa não deve ser o algo a mais, existe um equívoco. Agir de maneira acolhedora a fim de facilitar o desenvolvimento de um sujeito mais integrado não deve ser algo excepcional, mas sim uma prática natural, reconhece-se aqui o vício de recortar o que está inteiro.

Por fim, mais uma vez destacamos a importância do estudo e da prática da sensopercepção, segundo Levine e Frederick (1999) "viver sem a sensopercepção viola a experiência mais básica de estar vivo". Deixamos aqui nossa pequena contribuição em direção a este caminho que deve ainda ser explorado.

\title{
FELT SENSE DEVELOPMENT IN SWIMMERS: WORK MODEL AND RESULTS
}

\begin{abstract}
The felt sense is the perception of internal sensations that are generated through the body experience. Due to this reality, the Physical Education professional role becomes fundamental, once they conduct the bodily practices. The main objective of this study was to show the importance of swimming teacher in the development process of the felt sense. The appreciation of the felt sense can contribute not only for the technical development on the physical activities, but also promote on the students a better knowledge of taking care, respect and valorize their own body. The project showed to have a good adherence of the ones involved.
\end{abstract}

Keywords: Swimming;Sensation; Perception.

\section{DESARROLO DE LA PECEPCIÓN SENSORIAL EN NADADORES: MODELO DE TRABAJO Y RESULTADOS}

\section{Resumen}

La percepción sensorial es la percepción de sensaciones internas que se generan a través de la experiencia del cuerpo. Frente a esta realidad, el papel de la educación física también es crucial, ya que conduce a estas prácticas corporales. El objetivo de este estudio era demostrar la importancia del profesor de natación en el proceso de desarrollo de la percepción sensorial del estudiante. La apreciación del proceso de la percepción sensorial no sólo ha contribuido para ala mejora técnica en la práctica de la actividad física, y promovieran en los estudiantes/clientes un aprendizaje para mejor cuidar, valorar y respetar su propio cuerpo. El proyecto mostró una buena adherencia de los participantes.

Palabras Clave: Natación; Sensación; Percepción. 


\section{Referências}

American Psychological Association (APA). Diagnostic and Statistical Manual of Mental Disorders. Washington, DC: APA, 1994.

ANDRIES JÚNIOR, O., et. al. Nat AÇÃO. São Paulo: Plêiade, 2010.

BARDIN, L. Análise de conteúdo. Trad. Luís Antero Reto e Augusto Pinheiro. Lisboa: Edições 70, 2002.

CABRAL, S. Psicomotricidade relacional: prática clínica e escolar. São Paulo: Revinter, 2004

DAMASCENO, LG. Natação, psicomotricidade e desenvolvimento. Campinas: Autores Associados, 1997.

DAMÁSIO, A. E o cérebro criou o homem. São Paulo: Companhia das Letras, 2011.

GAMA E. F., et al. Influência da natação na percepção corporal. Revista Brasileira de Ciência e Movimento, v. 17, n 2, 2009

HANSON, Heidi. Peter Levine's Felt Sense Exercise. Healing from Trauma. Trauma Healing Resource Book Blog. 14 out 2013. Disponível em: http://http://www.newsynapse.com/aps/wordpress/?p=63. Acesso em: 18 out 2013.

LEVINE, P. A., FREDERICK, A. O despertar do tigre: curando o trauma. São Paulo: Summus, 1999.

LEVINE, P. A. Uma voz sem palavras: como o corpo libera o trauma e restaura o bem estar. São Paulo: Summus, 2012.

MAGLISCHO, E. W. Nadando Ainda Mais Rápido. Rio de Janeiro: Manole, 1999.

MARINA, J. Teoria da inteligência criadora. Lisboa: Caminho, 1995.

MINAYO, M.C.S. O desafio do conhecimento: pesquisa qualitativa em saúde. 6. ed. São Paulo: Rio de Janeiro: Abrasco; 1999

REIS, JW. A natação na sua expressão psicomotriz. Porto Alegre: Ed. da UFRGS, 1983.

TAVARES, M.C.G.C.F. Imagem corporal: conceito e desenvolvimento. Bareuri: Manole, 2003.

THOMAS, J.R.; NELSON, J.K. Métodos de pesquisa em atividade física. 3 ed. Porto Alegre, Artmed Editora, 2002. 
VANDENBOS, G.R (Org.) Dicionário de psicologia da APA. Porto Alegre: Artmed, 2010.

Recebido em: 05/02/2015

Revisado em: 07/03/2015

Aprovado em: 19/07/2015

Endereço para correspondência:

kawagosi.mie@gmail.com

Carolina Mie Kawagosi Onodera

Cidade Universitária Zeferino Vaz, Barão Geraldo

13083-878

Campinas, SP Brasil

Caixapostal: 6198 